\title{
Self-harm in UK armed forces personnel: descriptive and case-control study of general hospital presentations
}

Keith Hawton, Louise Harriss, Deborah Casey, Sue Simkin, Kate Harrison, Isabelle Bray and Nick Blatchley

\section{Background}

Little is known about self-harm in the armed forces.

\section{Aims}

To investigate the characteristics of armed forces personnel presenting to a general hospital following self-harm and compare these with matched controls who had selfharmed.

\section{Method}

Investigation of armed forces personnel presenting to hospital between 1989 and 2003 following self-harm and case-control comparison with people in the general population who had self-harmed.

\section{Results}

One hundred and sixty-six armed forces personnel presented with self-harm during the study period, of whom $72.3 \%$ (120) were male. Nearly two-thirds (62.7\%) were aged under 25 years. Relationship problems (62.0\%), employment problems (43.9\%) and alcohol misuse (40.5\%) were common. Fewer armed forces personnel than controls had evidence of current or past psychiatric disorders or treatment or a prior history of self-harm, and their suicidal intent was lower (males only). Of 64 people in the armed forces who presented during the first 9 years of the study period, 1 had died (from natural causes) by the end of 2000, compared with $9(5.1 \%)$ of the controls, 6 by probable suicide.

\section{Conclusions}

Self-harm by armed forces personnel may often be a response to interpersonal and employment problems complicated by alcohol misuse, with relatively low suicide intent.

\section{Declaration of interest}

K.Harrison, I.B. and N.B. Work for the Defence Analytical Services Agency, an agency of the Ministry of Defence (until March 2008, after which it was re-absorbed into the Ministry of Defence). The views expressed here do not necessarily represent those of the Ministry of Defence or Her Majesty's Government.
Suicide in armed forces personnel has recently attracted considerable media attention in the UK. However, rates of suicide have been generally lower in UK armed forces personnel than in people of similar age in the general population, ${ }^{1}$ with similar findings from the USA ${ }^{2}$ and Ireland, ${ }^{3}$ although higher than expected rates have been reported for young male army personnel in the UK. ${ }^{1}$ Less is known about self-harm in the UK armed forces, although a history of self-harm emerged as a risk factor for suicide when members of the Irish Defence Forces who died by suicide were compared with age- and gender-matched military controls. ${ }^{3}$ It is important to know more about self-harm in armed forces personnel because, in addition to signifying distress, self-harm generally has a strong association with risk of subsequent suicide. ${ }^{4-6}$

In a recent report based on self-harm in army personnel investigated by the Royal Military Police, self-harm was nearly two and a half times more frequent among females (annual rate 265 per $100000,95 \%$ CI $232-304)$ than males $(114,95 \% \mathrm{CI}$ 108-121). Approximately three-quarters of the cases occurred in personnel under 25 years of age, with a particularly high rate in under-20-year-old females $(895,95 \%$ CI $733-1092){ }^{7}$ However, the Royal Military Police investigate only a minority of cases (to ensure no illegal act has been committed). In addition, those identified may not be representative; for example, they may include more self-harm episodes which involve particularly dangerous methods of self-harm (e.g. hanging). Furthermore, individuals may be more likely to refuse to give information to other armed forces personnel. On the basis of an audit of self-harm in the Royal Navy from case records, self-harm rates of 22 per 100000 for males and 118 per 100000 for females were estimated. ${ }^{8}$ However, these figures were regarded as underestimates because of the difficulty of military doctors obtaining information about all cases. No information is available on self-harm by Royal Marines or Royal Air Force (RAF) personnel.

Most UK armed forces personnel who received hospital attention for self-harm during the period of this study will have been seen at civilian hospitals as a programme of closure of military hospitals was implemented in the early to mid-1990s. Therefore, research based on National Health Service hospital presentations that includes information on occupation could provide an important source of information on self-harm in the armed forces. This source of information would also have the potential advantage of being external to and independent of military organisations, and may be more likely to provide access to personal information such as psychiatric history and interpersonal and employment problems.

We have studied a series of individuals in the armed forces who self-harmed and presented to the general hospital in Oxford over a 15-year period. We have compared these with matched civilian controls presenting to the hospital following self-harm during the same time period. The main aims of the study were to investigate the characteristics of armed forces personnel who presented to hospital following self-harm, and to determine in what ways their characteristics differed from individuals who self-harm but are not in the armed forces.

\section{Method}

\section{Study population}

The study sample of individuals who had self-harmed was identified using the Oxford Monitoring System for Attempted 
Suicide database, through which information is collected on all people who have self-harmed presenting to the general hospital in Oxford. ${ }^{9,10}$ Self-harm is defined as intentional self-poisoning or self-injury, irrespective of the type of motivation or degree of suicidal intent.

The majority (approximately $80 \%$ ) of people presenting to the general hospital in Oxford following self-harm receive a psychosocial assessment conducted by a specially trained member of the hospital psychiatric service. Details of demographic and clinical characteristics are recorded by the clinical assessors on a structured form, and the data are subsequently coded and entered into a computer data file. A limited amount of information is also obtained from hospital records on individuals who have selfharmed but who have not been seen by the psychiatric service, who are identified through scrutiny of the computerised records of patients presenting to the Emergency Department. The overall method of ascertainment of cases has previously been shown to be reliable. ${ }^{11}$

\section{Selection of armed forces personnel}

Armed forces personnel who were based in Oxfordshire and who presented to the general hospital following self-harm between 1 January 1989 and 31 December 2003 were identified through routinely collected information on employment status. During the period of the study there were four major UK military sites in Oxfordshire, two being RAF stations, one an Army barracks, and one being an RAF station until 1992 and then becoming an Army barracks. There were also other small military units. It is estimated that annually some 8000 Service personnel were posted in Oxfordshire during the last 10 years of the period of this study, with possibly a few thousand more during the first few years. The population at risk cannot be defined accurately however, as Service personnel will have frequently been located in other areas for training, exercises and for operational deployments overseas or in Northern Ireland. Additionally, some small units may have been located closer to other hospitals in neighbouring counties. We have therefore not attempted to estimate rates of self-harm.

\section{Selection of controls}

Three control individuals per member of the armed forces who had self-harmed were selected from among all other individuals who presented for self-harm during the study period, matched for gender, age (in years), whether or not they received a psychosocial assessment in hospital, date of episode to within 6 months (before or after) and residence in Oxfordshire. If no age match could be found for a case, matching criteria were extended to include people 1 year older or younger, thus ensuring that it was possible to find three control individuals for each case.

\section{Information collected}

The information recorded by the Oxford Monitoring System includes details of demographic characteristics (e.g. gender, age, marital status, employment status, occupation, living situation), psychiatric care, previous self-harm episodes, method used in the present self-harm episode (including alcohol consumption), alcohol and drug misuse, parental status, violence, criminal record, problems, physical illness, suicide intent, and after-care offered. 'Alcohol misuse' is classified into chronic alcoholism with physical symptoms, alcohol dependence and excessive drinking (i.e. consumption of more than the maximum recommended number of units for men and women). 'Violence within the past 5 years' is defined as acts that either caused, or were likely to have caused, physical damage. 'Problems' are defined as factors that were causing current distress for the patient and/or contributed to the episode of self-harm. The nature of the employment problems of armed forces personnel were investigated in more detail, based on examination of case records and independent classification of the problems by each of four research team members. Since 1993, the level of suicidal intent associated with the episode of self-harm has been recorded using the Suicide Intent Scale. ${ }^{12-14}$ This includes two parts: the first concerns the objective circumstance of the act and the second the individual's self-reported intentions involved in the act.

For individuals in both the Service and control groups who presented to hospital between the beginning of 1989 and the end of 1997 we identified deaths (including cause) up until the end of 2000 through the Office for National Statistics for England and Wales, the Central Services Agency in Northern Ireland and the General Register Office for Scotland. ${ }^{5}$

\section{Statistical analysis}

All individuals were included in the analyses relating to age, gender, method of self-harm, and admission and assessment. The analyses of the remaining variables were restricted to those people who received a psychosocial assessment. For some of these variables there was incomplete information for a minority of people. For the case-control analysis of Suicide Intent Scale scores, the scores were categorised as either 'high' or 'low' on the basis of median scores. Where people had more than one episode of selfharm during the study period, their first episode was used as the index episode.

The characteristics of the armed forces personnel were analysed using $\chi^{2}$ and Fisher's exact tests. These analyses were conducted using SPSS version 12.0. ${ }^{15}$ Univariate and multivariate conditional logistic regression analyses were conducted to compare cases and controls using STATA version $8 .^{16}$

\section{Ethical approval}

The Oxford Monitoring System for Attempted Suicide is approved by the local research ethics committee. It has approval under Section 60 of the Health and Social Care Act 2001 to collect patient data without individual consent. It also complies with the Data Protection Act 1998.

\section{Results}

\section{Study sample}

During the 15-year study period (1989-2003) a total of 166 armed forces personnel (184 episodes) presented to the general hospital following self-harm (Table 1). The majority of the patients were male $(n=120,72.3 \%)$. Two-thirds of the males were in the Army, whereas nearly two-thirds of the females were in the RAF. Overall, the proportion of individuals who self-harmed in the two Services compared with the broad distribution of armed forces locally indicated that the Army was overrepresented among those who self-harmed. The number of Service personnel presenting following self-harm increased substantially during the study period, with an increase of $80.6 \%$ between 1989-1993 $(n=31)$ and 1994-1998 $(n=56)$, and a further increase of $41.1 \%$ between 1994-1998 and 1999-2003 ( $n=79)$.

The individuals who self-harmed in the armed forces were predominantly young (Table 1). Most (95.2\%) were under 35 years of age and nearly two-thirds $(62.7 \%)$ were under 25 years of age. Females in particular tended to be young, with nearly three-quarters $(73.9 \%)$ being in the 16-24 years age group. These 


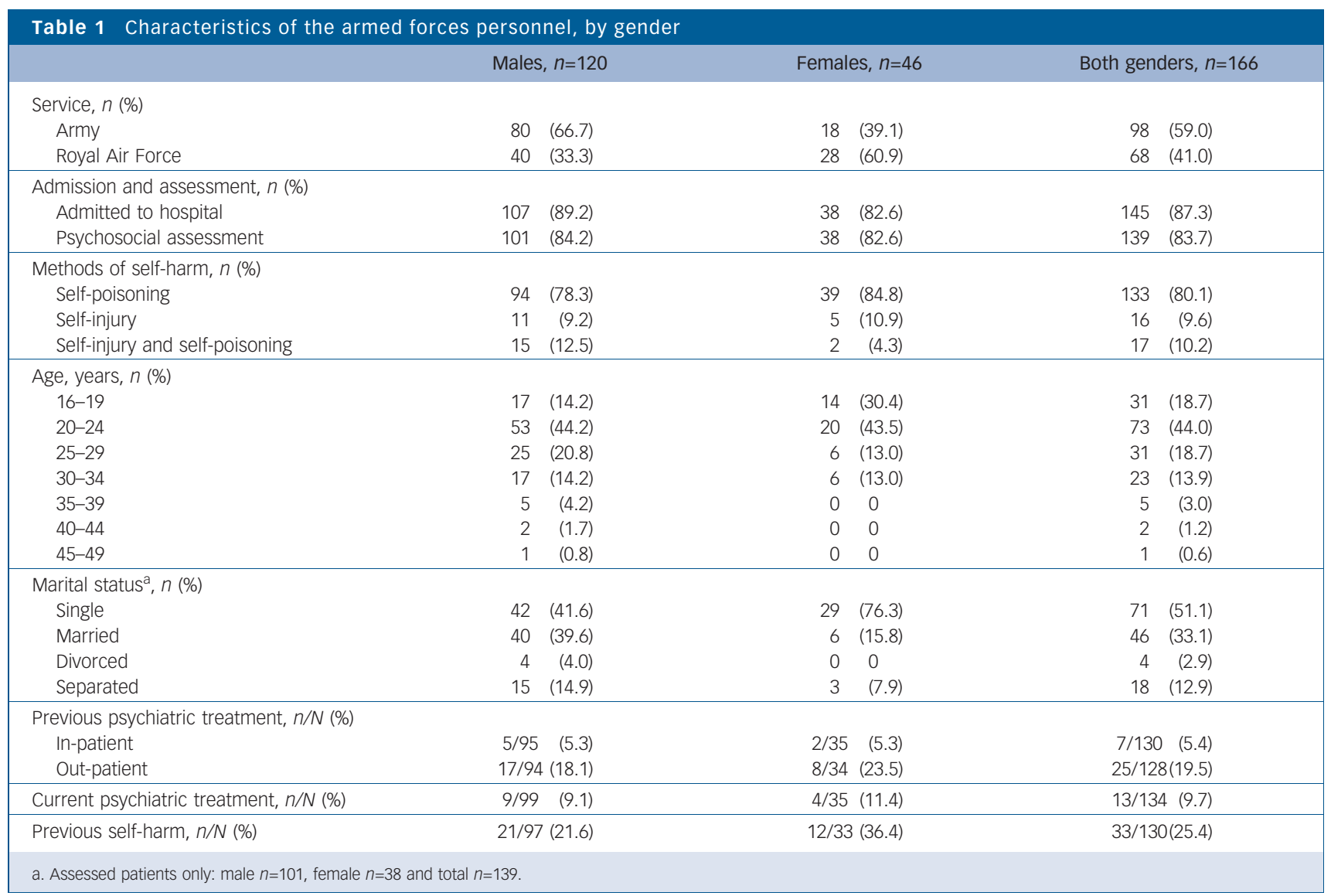

figures indicate a younger age distribution than in the armed forces in general.

\section{Methods of self-harm}

Four out of five $(80.1 \%)$ of the self-harm episodes by the armed forces personnel involved self-poisoning alone (Table 1). More than three-quarters of these involved non-opiate analgesics $(77.3 \%, 116 / 150)$. The next most frequently used groups of drugs were minor tranquillisers and sedatives $(9.3 \%, 14 / 150)$, followed by antidepressants $(7.3 \%, 11 / 150)$. Nearly a third of the overdoses involved a range of other prescribed drugs $(31.3 \%, 47 / 150)$. These included substances such as non-steroidal anti-inflammatory drugs and antibiotics.

Of the self-injuries (including those where self-harm also involved self-poisoning; Table 1), the predominant method was self-cutting $(81.8 \%, 27 / 33)$. All but 3 of the 27 cases of self-cutting involved cuts to the wrist and/or forearm. There were six selfharm episodes that involved other types of self-injury, five of these by males. Two were by hanging.

\section{Suicidal intent}

The majority of Suicide Intent Scale scores for the self-harm episodes (1993-2003) by the armed forces personnel were in the low $(0-6)(36.6 \%, 37 / 101)$ to moderate $(7-12)(39.6 \%, 40 / 101)$ range. This applied to a particularly large proportion of the selfharm episodes by males, with $41.0 \%(32 / 78)$ in the low range of scores and $35.9 \%(28 / 78)$ in the moderate range. Suicide intent scores for over half of the episodes by females were in the moderate range $(52.2 \%, 12 / 23)$. Suicide intent scores were available for five of the six individuals using other types of self-injury, only one of which had a score (22) in the high range. The scores for the other four people were low, ranging between 0 and 7 .

\section{Psychiatric and medical history}

A history of previous psychiatric treatment (i.e. treatment by a member of a psychiatric service) was relatively uncommon in the armed forces personnel (Table 1). Only 5.4\% had previously been admitted to psychiatric in-patient care and $19.5 \%$ treated as out-patients. A small proportion of individuals (9.7\%) were in psychiatric treatment at the time of their self-harm episodes. Physical illness (of any type) was relatively infrequent (15.1\%).

A quarter of armed forces personnel (25.4\%) had a history of at least one prior self-harm episode. Previous self-harm was somewhat more frequent in females than males $(36.4 \%$ v. $21.6 \%$, $\left.\chi^{2}=2.81, P=0.09\right)$. The figures for previous self-harm included episodes that had not involved hospital presentation as well as those that had. The former were relatively common, with 26 individuals having carried out self-harm episodes which did not involve presentation to hospital, and 17 having presented to hospital (some individuals were in both categories).

\section{Alcohol and drug use}

Alcohol had frequently been consumed within $6 \mathrm{~h}$ prior to selfharm $(57.5 \%, 77 / 134)$. Alcohol had less often been used as part of the self-harm act $(28.9 \%, 37 / 128)$.

Misuse of alcohol was common, mainly in the form of excessive drinking (i.e. drinking more than the recommended maximum number of units per week: $37.3 \%, 47 / 126)$. There were few cases of alcohol dependency $(3.2 \% ; 4 / 126)$. Drug misuse was uncommon $(5.7 \%, 7 / 125)$.

\section{Problems faced by individuals}

The most common type of problem faced by armed forces personnel concerned a relationship with a partner, with nearly two-thirds (62.0\%) having such problems. Employment problems 
were the next most frequent (43.9\%). A quarter of the individuals (25.9\%) had problems relating to the use of alcohol. Nearly one in five people $(18.8 \%)$ had problems concerning relationships with family members. Other problems occurred less frequently.

The following are details of the nature of the employment problems based on scrutiny of descriptions and quotations in case notes. Many individuals with employment problems had problems of more than one type. The most common type of employment problem concerned specific difficulties relating to the individual's job within the Forces. Nearly one in five individuals $(19.4 \%, 27)$ had difficulties of this kind, including the job being stressful, disliking the job, the job being boring and repetitive, and failure to progress or be promoted. A substantial minority $(17.3 \%, 24)$ indicated that they wished to leave their Service. One in six individuals $(16.5 \%, 23)$ made specific complaints about their lifestyle in the Forces. Relationship issues within the Forces were another source of difficulty, especially difficulties with colleagues, being mentioned by 19 (13.7\%) individuals. Physical aggression was a feature of some of these problems. More than one in ten $(11.5 \%$, 16) individuals were facing, or had recently faced, disciplinary problems. These were mostly related to military disciplinary issues, although in other cases consequences of civilian offences (e.g. being convicted of a driving offence) were having a major effect on the person's job, which for some people included their having to change role (e.g. to a non-driving job). Four individuals had problems related to specific military operations.

\section{After-care offered}

Approximately a quarter of the individuals $(26.6 \%, 37 / 139)$ who were assessed were offered psychiatric out-patient care following discharge from hospital. The majority of these $(67.6 \%, 25 / 37)$ were referred to the armed forces healthcare service. Only eight people $(5.8 \%)$ were admitted to psychiatric in-patient care, of whom three were admitted to a military hospital. Over half of individuals $(59.7 \%)$ were referred back to their general practitioner, who in many cases would have been an armed forces medical officer.

\section{Case-control comparison}

Comparison of the armed forces personnel with their civilian controls showed that the former were less likely to be single (Table 2). They were also less likely than the controls to have been in psychiatric care at the time of self-harm, to have had previous psychiatric care and to have a history of previous self-harm.

The methods used for self-harm by the armed forces personnel more often involved self-poisoning. There was little difference in the proportions of armed forces personnel and controls with high total Suicide Intent Scale scores (based on a median score for the two genders of 9.0). However, significantly fewer of the armed forces personnel had high scores on the self-report (Part II) section of the scale. People in the armed forces were far less likely to have a history of drug misuse or to have received a diagnosis of psychiatric or personality disorder at the time of self-harm. Fewer of the armed forces personnel were offered psychiatric after-care after the self-harm episode, including psychiatric in-patient care.

At the time of self-harm, more armed forces personnel were facing problems concerning a relationship with a partner and employment. Problems that were less common than in the controls included those concerning relationships with family members, psychiatric disorders, relationships with friends,

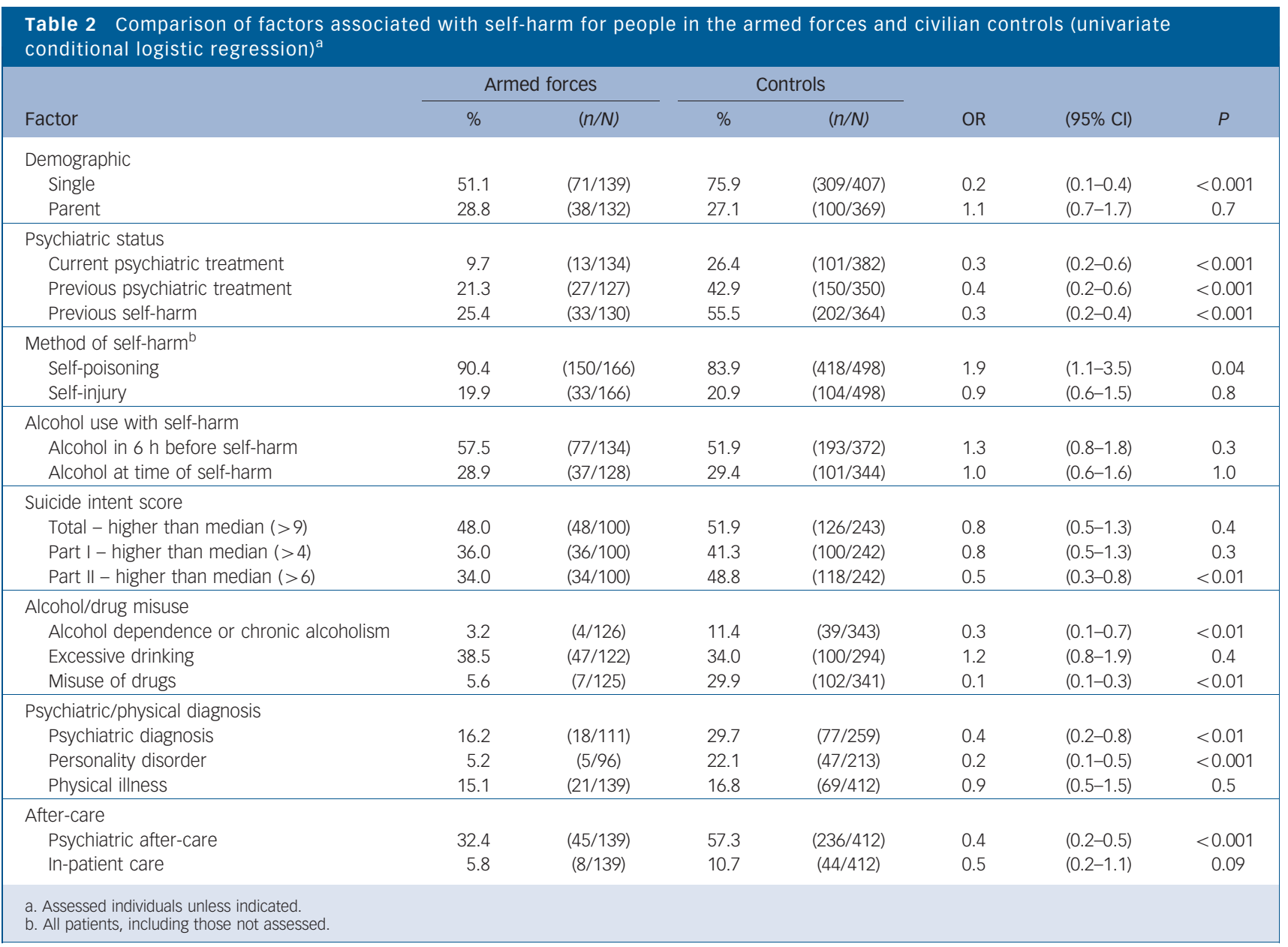


housing and drugs (Table 3). When the analyses were re-run omitting all the unemployed controls, essentially the same results emerged (including a significant excess of service personnel with employment problems).

Multivariate comparison of armed forces personnel and controls on personal and clinical characteristics and problems indicated that the only factor that was significantly more frequent in the Service personnel was employment problems (odds ratio $\mathrm{OR}=2.2$, 95\% CI 1.2-3.9). Less frequent factors were being single ( $\mathrm{OR}=0.3,95 \% \mathrm{CI} 0.1-0.5)$, previous self-harm $(\mathrm{OR}=0.3$, 95\% CI 0.1-0.5), drug misuse (OR=0.1, 95\% CI 0.03-0.4) and problems in relationships with friends $(\mathrm{OR}=0.2,95 \%$ CI $0.1-0.5)$.

Males

Most of the differences found in the case-control comparisons for both genders together were also found when the male cases and controls were compared separately, including findings based on the multivariate analysis. Fewer male armed forces personnel had high Suicide Intent Scale scores than did their controls (36.4\% (28/77) v. 53.2\% (99/186), OR=0.5, 95\% CI 0.3-0.9).

Females

There were few significant differences between the female armed forces personnel and their controls, which partly may have reflected the smaller numbers of women in the sample. Fewer of the female armed forces personnel were in psychiatric care at the time of self-harm $(11.4 \%(4 / 35)$ v. $34.3 \%$ (34/99), OR=0.3, 95\% CI 0.1-0.8) and far more had drunk alcohol during the $6 \mathrm{~h}$ before self-harm $(65.7 \%$ (23/35) v. 39.6\% (38/96), OR=2.6, 95\% CI 1.2-5.9). More of the female armed forces personnel had problems relating to employment $(47.4 \%$ (18/38) v. $26.4 \%$ (29/ $110), \mathrm{OR}=2.6,95 \% \mathrm{CI} 1.1-5.8)$. Fewer of the women in the armed forces received a psychiatric diagnosis at the time of self-harm
(15.2\% (5/33) v. 39.7\% (31/78), OR=0.3, 95\% CI 0.1-0.8), or were offered psychiatric after-care $(31.6 \%(12 / 38)$ v. 53.6\% (60/112), $\mathrm{OR}=0.4,95 \%$ CI $0.2-0.3$ ).

Multivariate analysis of factors including personal and clinical characteristics and problems indicated that the factors that were independently more frequent in the female Service personnel were use of alcohol within $6 \mathrm{~h}$ before self-harm $(\mathrm{OR}=2.3,95 \% \mathrm{CI} 1.2-$ 6.2) and employment problems ( $\mathrm{OR}=2.7,95 \%$ CI 1.1-6.3).

\section{Deaths}

Of 64 armed forces personnel who presented with self-harm between the beginning of 1989 and the end of 1997, one male $(1.6 \%, 95 \%$ CI $0.0-9.0 \%)$ had died by the end of 2000 . The cause was not related to suicide. Of the 175 controls for these individuals, 9 (5.1\%, 95\% CI 2.3-9.8\%) people had died. These were all males. In 6 of these cases, a verdict of either suicide or undetermined cause (open verdict) had been recorded.

\section{Discussion}

This study was based on all UK armed forces personnel who presented to a general hospital following self-harm. The marked increase in the number of presentations of armed forces personnel during the 15-year study period may partly have reflected an underlying increase in self-harm in the general population during this time period. ${ }^{10}$ It may also represent a real increase in selfharm in the armed forces, since although population figures for the armed forces in Oxfordshire during the study period are unavailable it is known that the number of Service personnel did not change greatly. It could also be because of an increased likelihood over time of armed forces personnel being prepared to reveal their occupation because of changing levels of security

Table 3 Comparison of problems faced by people who self-harmed in the armed forces and civilian controls (univariate conditional logistic regression) $)^{\mathrm{a}}$

\begin{tabular}{|c|c|c|c|c|c|c|c|}
\hline \multirow[b]{2}{*}{ Problem } & \multicolumn{2}{|c|}{ Armed forces } & \multicolumn{2}{|c|}{ Controls } & \multirow[b]{2}{*}{ OR } & \multirow[b]{2}{*}{$(95 \% \mathrm{Cl})$} & \multirow[b]{2}{*}{$P$} \\
\hline & $\%^{\mathrm{b}}$ & $(n / N)$ & $\%^{\mathrm{b}}$ & $(n / N)$ & & & \\
\hline Relationship with partner & 62.0 & $(85 / 137)$ & 50.9 & $(200 / 393)$ & 1.6 & $(1.1-2.4)$ & $<0.03$ \\
\hline Employment & 43.9 & $(61 / 139)$ & 33.5 & $(134 / 400)$ & 1.5 & $(1.0-2.3)$ & $<0.04$ \\
\hline Alcohol & 25.9 & $(36 / 139)$ & 29.8 & $(119 / 400)$ & 0.8 & $(0.5-1.2)$ & 0.4 \\
\hline Relationship with family & 18.8 & $(28 / 139)$ & 33.8 & $(135 / 400)$ & 0.5 & $(0.3-0.8)$ & $<0.005$ \\
\hline Financial & 18.0 & $(25 / 139)$ & 21.8 & $(87 / 400)$ & 0.8 & $(0.5-1.3)$ & 0.4 \\
\hline Social isolation & 10.8 & $(15 / 139)$ & 17.0 & $(68 / 400)$ & 0.6 & $(0.3-1.0)$ & 0.06 \\
\hline Psychiatric disorder & 8.6 & $(12 / 139)$ & 18.0 & $(72 / 400)$ & 0.4 & $(0.2-0.8)$ & $<0.01$ \\
\hline Bereavement/loss & 7.9 & $(11 / 139)$ & 10.0 & $(40 / 400)$ & 0.8 & $(0.4-1.6)$ & 0.5 \\
\hline Physical health & 7.9 & $(10 / 139)$ & 5.0 & $(20 / 400)$ & 1.5 & $(0.7-3.2)$ & 0.3 \\
\hline Relationship with friends & 6.5 & $(9 / 139)$ & 15.8 & $(63 / 400)$ & 0.3 & $(0.2-0.7)$ & $<0.005$ \\
\hline Legal & 5.0 & (7/139) & 6.3 & $(25 / 400)$ & 0.8 & $(0.3-1.9)$ & 0.6 \\
\hline Housing & 3.6 & $(5 / 139)$ & 17.5 & $(70 / 400)$ & 0.2 & $(0.1-0.5)$ & $<0.001$ \\
\hline Drugs & 3.6 & $(5 / 139)$ & 16.0 & $(64 / 400)$ & 0.2 & $(0.1-0.5)$ & $<0.001$ \\
\hline Childhood sexual abuse $^{c}$ & 2.3 & $(3 / 130)$ & 4.5 & $(17 / 376)$ & 0.5 & $(0.1-1.7)$ & 0.3 \\
\hline Sexual adjustment & 1.4 & $(2 / 139)$ & 3.0 & $(12 / 400)$ & 0.4 & $(0.08-2.0)$ & 0.3 \\
\hline Chronic pain $^{d}$ & 1.3 & $(1 / 80)$ & 1.3 & $(3 / 233)$ & 0.9 & $(0.1-8.7)$ & 0.9 \\
\hline Eating disorder & 0.7 & $(1 / 139)$ & 2.8 & $(11 / 400)$ & 0.2 & $(0.03-1.8)$ & 0.2 \\
\hline Childhood physical abuse & 0 & $(0 / 7)$ & 11.1 & $(2 / 18)$ & - & - & - \\
\hline Childhood neglect & 0 & $(0 / 7)$ & 5.9 & $(1 / 17)$ & - & - & - \\
\hline Repetitive self-mutilation & 0 & $(0 / 130)$ & 4.8 & $(19 / 376)$ & - & - & - \\
\hline \multicolumn{8}{|c|}{$\begin{array}{l}\text { a. Assessed individuals. } \\
\text { b. Multiple problems were recorded for many patients, hence the total percentages exceed 100\%. } \\
\text { c. Consequences of childhood sexual abuse were recorded from } 1992 \text { onwards. } \\
\text { d. Chronic pain was recorded from } 1998 \text { onwards. }\end{array}$} \\
\hline
\end{tabular}


concerns, perceived reduction in stigma associated with self-harm and mental health problems in general in the armed forces, and a changed profile of the relative numbers of personnel in the Army and the RAF, which may themselves exhibit different risks of self-harm.

\section{Characteristics of people who self-harm in the armed forces}

One of the main aims of this study was to investigate the characteristics of the armed forces personnel who presented with self-harm. Although nearly three-quarters were male, this is considerably lower than the proportion of males in the Army and RAF in 1990 (94.3\%) and in 2003 (91.4\%). Thus, female armed forces personnel were overrepresented in the self-harm population. Although self-harm is also more common in females in the general population, ${ }^{10}$ the risk in females in the armed forces may be even more elevated. ${ }^{7}$ The armed forces personnel were predominantly young, nearly all being under 35 years of age. Almost three-quarters of the females were under 25 years old, which is consistent with the particularly high rate of self-harm in young females in the armed forces found in another study. ${ }^{7}$

Nine out of ten of the self-harm episodes involved selfpoisoning. As in self-harm patients in general, ${ }^{10}$ the predominant method of self-injury was self-cutting, usually of the wrist and/or forearm. Of five incidences of other types of self-injury, which included potentially more lethal methods, only one appeared to involve high suicide intent. Thus, there was little evidence to suggest that these cases represented failed suicide attempts. Alcohol consumption in relation to the self-harm episodes was common, especially in the female armed forces personnel.

There were several differences between armed forces personnel who self-harmed and other people who self-harmed. In particular, self-harm appeared to be less often related to psychiatric disorders. Thus, far fewer of the armed forces personnel than their controls had received psychiatric treatment prior to the self-harm episode, and fewer were assessed as having psychiatric disorders or personality disorders at the time of self-harm, although minimisation of symptoms due to perceived stigma may have influenced these findings. A history of previous self-harm was also far less common than in the controls. However, very often this history included acts that had not resulted in presentation to hospitals, in addition to acts which had, which suggests that there may be a sizeable problem of self-harm in the armed forces that does not come to clinical attention - as is also the case in the general population. ${ }^{17,18}$

Misuse of alcohol was common in the armed forces personnel, which is recognised as a general issue for the Services. ${ }^{19}$ However, this was rarely of a degree indicative of alcohol dependence, which was significantly less common than in the controls. There were also far fewer cases of drug misuse than in the controls. This may reflect the compulsory drug testing programme in the armed forces and the fact that drug misuse is a reason for dismissal. ${ }^{20}$ By far the most frequent type of problem identified in people who received a clinical assessment concerned a relationship with a partner, this being significantly more frequent than in the controls.

Employment problems were more frequent in the armed forces personnel than the controls, despite all the armed forces personnel being in a relatively stable occupation. The types of employment problems were diverse, the most common being a specific difficulty an individual had with their job in the armed forces, such as finding it stressful or boring, wanting to leave their Service, relationship difficulties with colleagues and disciplinary problems.

Psychiatric service after-care was offered to significantly fewer of the armed forces personnel than their controls. This was in keeping with the generally lower frequency of psychiatric disorder in the armed forces personnel in this study.

Relatively few of the acts of self-harm by armed forces personnel appeared to have been intended to result in death. This was true especially of the males, as reflected in the case-control comparison of suicide intent scores. Although this could have reflected less willingness to admit intent, it was in keeping with the low incidence of mental health problems in the armed forces personnel and probably with the strong association of self-harm with interpersonal and employment problems, and also alcohol consumption. ${ }^{13}$

\section{Limitations of the study}

This study has several limitations. We cannot be certain that our sample is representative of all individuals who self-harm within the military as there may be factors which determine presentation at a civilian rather than a military hospital, of which expediency in an emergency is likely to be the main one (however, since 1996, there has been no military hospital in the catchment area). Also, the military population in Oxfordshire, although extensive, cannot be said to be representative of the UK armed forces as it includes an excess of RAF relative to Army personnel and does not include Naval Service personnel. Another limitation is that the identification of armed forces personnel depended on individuals being willing to admit to being in a Service. Some individuals may have been unwilling to reveal their occupation and this may have changed over time. Controls were matched with armed forces personnel on the basis of a limited number of factors: gender, age, date of episode, residence within Oxfordshire and assessment status. It could be argued that matching on other variables (e.g. currently employed) might have avoided confounding for certain factors (e.g. psychiatric history). However, over-matching can risk failure to detect important differences. Finally, we have not been able to investigate the nature and extent of after-care actually received following self-harm.

\section{Implications}

Most of the self-harm acts by the armed forces personnel in this study, especially the males, appeared to be of low suicidal intent. It is notable that there were no suicides in the individuals included in the mortality follow-up, although the power of that part of the study was insufficient to demonstrate a significant difference. Selfharm is none the less a risk factor for suicide in military personnel in other countries, ${ }^{3}$ as in other populations. ${ }^{5,6}$

The main types of problems the armed forces personnel were facing were relationship problems, employment difficulties and problems concerning the use of alcohol. The relatively low level of psychiatric disorder yet high levels of relationship and employment problems suggest that self-harm by armed forces personnel is often used as a means of communicating distress related to current personal circumstances. The large proportion of individuals with relationship difficulties may reflect particular stresses that an armed forces lifestyle may place on relationships.

Alcohol often played a role in self-harm by the armed forces personnel, as also found in an audit of self-harm in Navy personnel. $^{21}$ Although alcohol misuse was no greater than in controls it could be argued that the levels of misuse are high in these individuals given their specific occupation. Alcohol misuse in the armed forces is recognised as a general issue. ${ }^{19}$ Alcohol appeared to have a particularly significant role in the self-harm episodes of the female armed forces personnel, since two-thirds had been drinking in the $6 \mathrm{~h}$ before the act. Strategies aimed at 
reducing heavy drinking within the armed forces could have a role in preventing self-harm. ${ }^{19,22}$

Possible future directions for research include: identifying at what stage in an armed forces career individuals are most at risk of self-harm; investigating the interactions between factors that contribute to self-harm by armed forces personnel, especially relationship problems, employment problems, alcohol, suicidal intent and availability of means for self-harm; studying the nature, uptake and effectiveness of after-care provided for armed forces personnel following self-harm; and long-term follow-up of larger numbers of such individuals to clarify the significance self-harm has for their subsequent progress in terms of emotional and occupational adjustment within the armed forces and after leaving the Service, and the risk of further self-harming behaviour, including suicide.

Keith Hawton, DSC, Louise Harriss, MSC, Deborah Casey, BSC, Sue Simkin, BA Centre for Suicide Research, University Department of Psychiatry, Warneford Hospital, Oxford; Kate Harrison, PhD, Isabelle Bray, PhD, Nick Blatchley, BSc, Defence Analytical Services and Advice (Health Information), Ensleigh, Bath, UK

Correspondence: Keith Hawton, Centre for Suicide Research, University Department of Psychiatry, Warneford Hospital, Oxford OX3 7JX, UK. Email: keith.hawton@psych.ox.ac.uk

First received 5 Dec 2007, final revision 13 Aug 2008, accepted 8 Sep 2008

\section{Acknowledgements}

This study was commissioned and funded by the Ministry of Defence, but no restraint were placed on the reporting of the findings. The Oxford Monitoring system for Attempted suicide is funded by the Department of Health. The views expressed here are those of the authors and not necessarily those of the Department of Health. We thank the members of the Barnes Unit clinical team at the John Radcliffe Hospital for recording information on patients seen by the service, Liz Bale, Anna Shepherd and Alison Bond for their help with data collection, and Emily Hargus for helping with collecting information on employment problems.

\section{References}

1 DASA. Suicides and open verdict deaths in the UK Regular Armed Forces 1984-2007. Ministry of Defence, 2008.

2 Rothberg JM, Bartone PT, Holloway HC, Marlowe DH. Life and death in the US army. In corpore sano. JAMA 1990; 264: 2241-4.

3 Mahon MJ, Tobin JP, Cusack DA, Kelleher C, Malone KM. Suicide among regular-duty military personnel: a retrospective case-control study of occupation-specific risk factors for workplace suicide. Am J Psychiatry 2005; 162: $1688-96$
4 Hawton K, Fagg J. Suicide, and other causes of death, following attempted suicide. Br J Psychiatry 1988; 152: 359-66.

5 Hawton K, Zahl D, Weatherall R. Suicide following deliberate self-harm: long-term follow-up of patients who presented to a general hospital. Br J Psychiatry 2003; 182: 537-42.

6 Owens D, Horrocks J, House A. Fatal and non-fatal repetition of self-harm. Systematic review. Br J Psychiatry 2002; 181: 193-9.

7 Blatchley NF, Ward VR, Davison LC, Harrison K, Fear NT. Deliberate Self-Harm in the Regular Army: A report on available data. DASA, Ministry of Defence, 2005.

8 Slaven G, Sharpley J. INM Report No. 2002.032 Audit of Deliberate Self Harm Cases in the Naval Service 1999-2001. Institute of Naval Medicine, 2002.

9 Hawton K, Fagg J, Simkin S, Bale E, Bond A. Trends in deliberate self-harm in Oxford, 1985-1995. Implications for clinical services and the prevention of suicide. Br J Psychiatry 1997; 171: 556-60.

10 Hawton K, Harriss L, Hall S, Simkin S, Bale E, Bond A. Deliberate self-harm in Oxford, 1990-2000: a time of change in patient characteristics. Psychol Med 2003; 33: 987-96.

11 Sellar C, Goldacre MJ, Hawton K. Reliability of routine hospital data on poisoning as measures of deliberate self poisoning in adolescents. J Epidemiol Community Health 1990; 44: 313-5.

12 Beck AT, Schuyler D, Herman I. Development of Suicidal Intent Scales. In The Prediction of Suicide (eds AT Beck, HLP Resnik, DJ Lettieri): 45-56. Charles Press, 1974

13 Harriss L, Hawton K, Zahl D. Value of measuring suicidal intent in the assessment of people attending hospital following self-poisoning or selfinjury. Br J Psychiatry 2005; 186: 60-6.

14 Harriss L, Hawton $\mathrm{K}$. Suicidal intent in deliberate self-harm and the risk of suicide: the predictive power of the Suicide Intent Scale. J Affect Disord 2005; 86: 225-33.

15 SPSS Inc. SPSS for Windows Release 12. SPSS Inc, 2003.

16 Stata Corporation. Intercooled Stata 8.0 for Windows. Stata Corporation, 2003.

17 Hawton $\mathrm{K}$, Rodham $\mathrm{K}$, Evans $\mathrm{E}$, weatherall $\mathrm{R}$. Deliberate self-harm in adolescents: self report survey in schools in England. BMJ 2002; 325: 1207-11.

18 Guthrie E, Kapur N, Mackway-Jones K, Chew-Graham C, Moorey J, Mendel E, et al. Randomised controlled trial of brief psychological intervention after deliberate self poisoning. BMJ 2001; 323: 135-7.

19 Fear NT, Iversen A, Meltzer H, Workman L, Hull L, Greenberg N, et al. Patterns of drinking in the UK Armed Forces. Addiction 2007; 102: 1749-59.

20 Bird SM. Compulsory drugs testing in the British Army. RUSI Journal 2007; 152: $54-9$.

21 Micklewright S. Deliberate self harm in the Royal Navy. An audit of cases presenting to the Department of Community Mental Health, RH Haslar between 1 March 1999 and 28 February 2002. J Royal Naval Med Serv 2005; 91: 12-25.

22 Rossow I. Substance use and suicidal behaviour. In Prevention and Treatment of Suicidal Behaviour: From Science to Practice (ed K Hawton): 261-77. Oxford University Press, 2005. 